\title{
Blood pressure and body mass index in an ethnically diverse sample of adolescents in Paramaribo, Suriname Charles Agyemang*1, Eline Oudeman ${ }^{1}$, Wilco Zijlmans ${ }^{2}$, Johannes Wendte ${ }^{1}$ and Karien Stronks ${ }^{1}$
}

\author{
Address: ${ }^{1}$ Department of Social Medicine, Academic Medical Centre, Amsterdam, The Netherlands and ${ }^{2}$ Department of Pediatrics, Diakonessen \\ Hospital, Paramaribo, Suriname \\ Email: Charles Agyemang* - c.o.agyemang@amc.uva.nl; Eline Oudeman - elineoudeman@ hotmail.com; \\ Wilco Zijlmans - cwrzijlmans@gmail.com; Johannes Wendte - j.f.wendte@amc.uva.nl; Karien Stronks - k.stronks@amc.uva.nl \\ * Corresponding author
}

Published: 21 May 2009

BMC Cardiovascular Disorders 2009, 9:19 doi:10.1186/1471-2261-9-19

This article is available from: http://www.biomedcentral.com/|47|-226I/9/19

(C) 2009 Agyemang et al; licensee BioMed Central Ltd.

This is an Open Access article distributed under the terms of the Creative Commons Attribution License (http://creativecommons.org/licenses/by/2.0), which permits unrestricted use, distribution, and reproduction in any medium, provided the original work is properly cited.
Received: 2 October 2008

Accepted: 21 May 2009

\begin{abstract}
Background: High blood pressure (BP) is now an important public health problem in nonindustrialised countries. The limited evidence suggests ethnic inequalities in BP in adults in some non-industrialised countries. However, it is unclear whether these ethnic inequalities in BP patterns in adults reflect on adolescents. Hence, we assessed ethnic differences in BP, and the association of BP with body mass index (BMI) among adolescents aged I2-17 years in Paramaribo, Suriname.
\end{abstract}

Methods: Cross-sectional study with anthropometric and blood pressure measurements. A random sample of 855 adolescents (167 Hindustanis, 169 Creoles, 128 Javanese, 91 Maroons and 300 mixed-ethnicities) were studied. Ethnicity was based on self-reported ethnic origin.

Results: Among boys, Maroons had a lower age- and height-adjusted systolic BP than Creoles, and a lower diastolic BP than other ethnic groups. However, after further adjustment for BMI, only diastolic BP in Maroons was significantly lower than in Javanese (67.1 versus $70.9 \mathrm{mmHg})$. Creole boys had a lower diastolic BP than Hindustani $(67.3$ versus $70.2 \mathrm{mmHg})$ and Javanese boys after adjustment for age, height and BMI. Among girls, there were no significant differences in systolic BP between the ethnic groups. Maroon girls, however, had a lower diastolic BP $(65.6 \mathrm{mmHg})$ than Hindustani $(69.1 \mathrm{mmHg})$, Javanese $(71.2 \mathrm{mmHg})$ and Mixed-ethnic $(68.3 \mathrm{mmHg})$ girls, but only after differences in BMI had been adjusted for. Javanese had a higher diastolic BP than Creoles (7I.2 versus $66.8 \mathrm{mmHg}$ ) and Mixed-ethnicity girls. BMI was positively associated with BP in all the ethnic groups, except for diastolic BP in Maroon girls.

Conclusion: The study findings indicate higher mean BP levels among Javanese and Hindustani adolescents compared with their African descent peers. These findings contrast the relatively low BP reported in Javanese and Hindustani adult populations in Suriname and underscore the need for public health measures early in life to prevent high BP and its sequelae in later life. 


\section{Background}

The increasing prevalence of cardiovascular diseases (CVD) is putting a tremendous pressure on already overburdened resources in non-industrialised countries. [1] High blood pressure (BP) is a leading cause of CVD. [2] The rising prevalence of hypertension in non-industrialised countries reflects well on the high prevalence of CVD. [2]

In children, BP tracking patterns confirm that persistent $\mathrm{BP}$ increase may be related to hypertension in adulthood. [3-5] Increased BP in childhood has also been linked with left ventricular hypertrophy. [6] Consequently, in most industrialised countries assessment and management of $\mathrm{BP}$ in childhood is strongly recommended to promote improved cardiovascular health in adulthood. [7] However, in some non-industrialised countries, BP data on children and adolescents are very scarce. In Suriname, for example, there is no published data on BP in children and adolescents. Information on BP in adults in Suriname is also very limited. A report from II PAHO-DOTA Workshop on Quality of Diabetes Care in 2003 indicates that hypertension is a major public health burden with prevalence rates ranging from $24 \%$ in Javanese to as high as $33 \%$ in African-Surinamese in Suriname. [8] The annual report of the Regional Health Service in 2000 also showed that hypertension care alone accounted for $15 \%$ of the total number of consultations. [8] This reflected the mortality data with CVD being the leading cause of death in Suriname.

Suriname's population is made up of several ethnic groups. As in industrialised countries, [9-12] the limited data in Suriname suggest ethnic inequalities in BP and hypertension in adults. [8] However, it is unclear whether these BP patterns in adults reflect on adolescents. In some industrialised countries such as the UK, ethnic differences in BP in adults [9-12] do not correspond with children's and adolescents' BP patterns. [13,14] In addition, the prevalence of overweight and obesity in children and adolescent have increased dramatically over the past few decades. This may have an impact on BP. In the United States of America, for example, overweight children have been shown to be 2-4 times more likely than non-overweight children to have high BP. [15-17] However, information on the relationship between body sizes and BP among different ethnic groups in non industrialised countries is limited. There is an urgent need for research in children and adolescents so that appropriate cost-effective interventions can be introduced early in life to prevent the burden of CVD in adulthood. $[18,19]$ The main objective of this study was to assess BP patterns, and to determine the association of BP with BMI among adolescents from different ethnic backgrounds in Paramaribo, Suriname. We hypothesised that the BP patterns in adults would reflect adolescents' BP patterns in various ethnic groups in Suriname.

\section{Methods \\ Study area}

Suriname is located in Northern South America. It borders French-Guyana to the east, British-Guyana to the west, Brazil to the south and the Atlantic Ocean to the north (Figure 1). It has a total area of 163,820 square kilometres. According to the World Factbook, the total population in 2007 was about 449,000 people. The life expectancy was 66 years for men and 71 years for women. Suriname's population is made up of several ethnic groups: Hindustani, Creoles, Javanese, Maroons, Amerindian, Chinese, White and other. About $28 \%$ of the population is under 15 years of age (ca. 132,000). Data for this study were collected between March and June 2007 in Paramaribo, the capital city of Suriname. The vast majority of people (about 90\%) live in Paramaribo and its surroundings.

\section{Study design}

Data were collected in nine schools among healthy adolescents between the ages of 12 to17 years. All schools were randomly selected from the 103 government schools' list. The schools were visited prior to data collection to obtain permission from the relevant school principals as well as from the pupils. After agreeing to this, participants were advised not to smoke, drink alcohol or take vigorous exercise during the 30 minutes preceding the BP measurement. Data collection took place during normal school hours. Verbal informed consent was sought from each participant before measurements were taken. None of the children refused to participate in this study. Forty three children were excluded because they were below 12 years old, and one child was excluded because she reported suffering from severe heart disease. The Ethical Board of the Ministry of Education in Suriname approved the study protocols.

\section{Measurements}

Height was measured without shoes with a measuring tape to the nearest 0.01 metre. Weight was measured to the nearest $0.1 \mathrm{~kg}$ after removal of shoes, jackets, heavy clothing and pocket contents (using an Electronic Korona Profirmed scale). BMI was calculated as weight divided by height squared $\left(\mathrm{kg} / \mathrm{m}^{2}\right)$. Overweight and obesity were defined using the sex- and age-specific BMI criteria of the International Obesity Task Force. [20] BP was measured in the morning with a validated oscillometric automated digital BP device (Omron M-5, Japan). Using appropriate cuff sizes, three readings with one minute interval were taken on the right arm in a seated position after at least five minutes rest. The mean of the last two readings was used for analysis. Sex-, age- and height-specific percentile levels were defined using US normative BP tables for chil- 


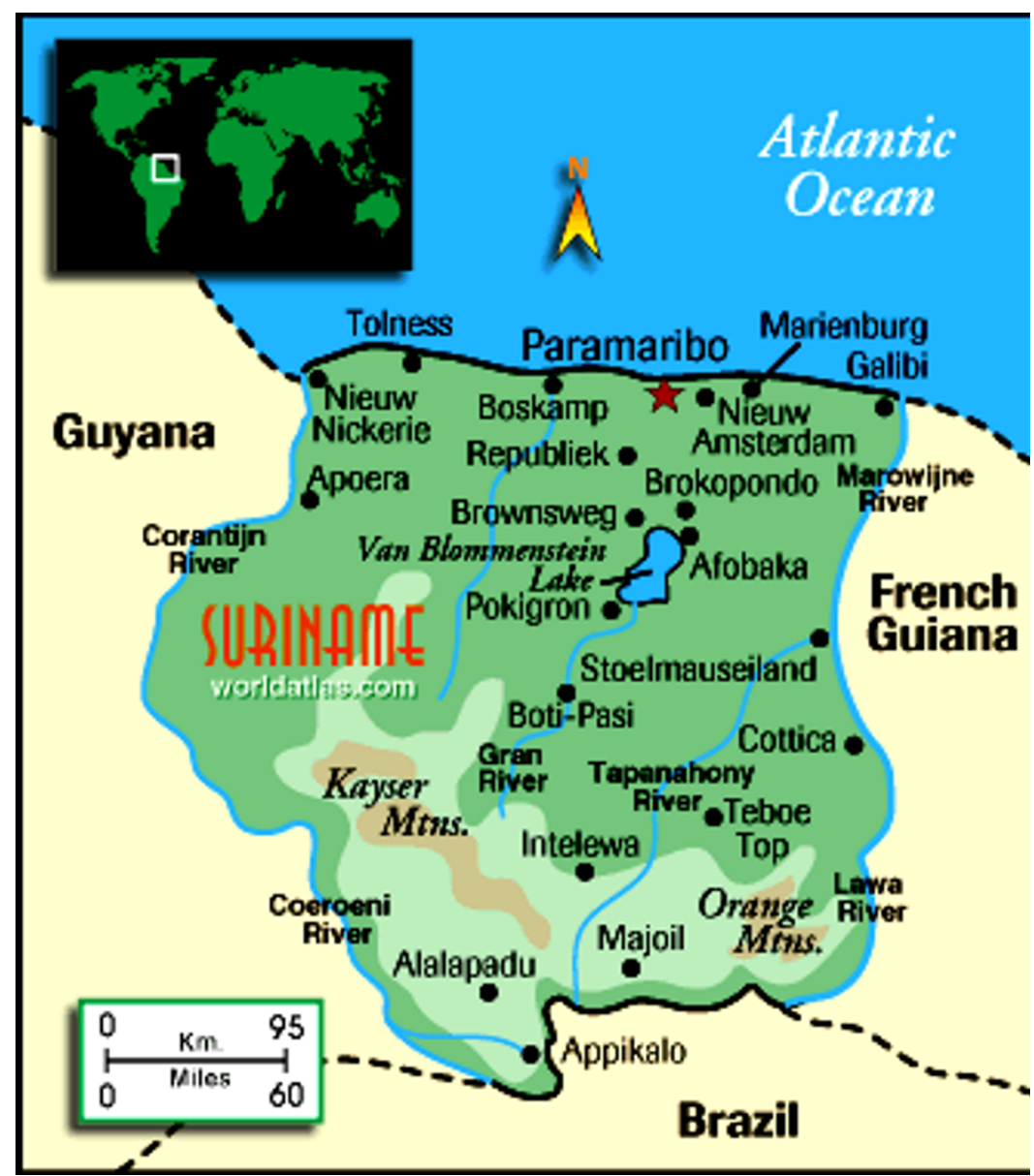

Figure I

Map of Suriname.

dren and adolescents. [21] High BP was defined as systolic $\mathrm{BP}$ and/or diastolic $\mathrm{BP} \geq 95$ th percentile. [21]

In addition to the physical measurements, participants were asked to complete a short questionnaire including questions on age, sex, ethnic background and physical activity. The ethnicity of these groups was identified using self-reported ethnicity. Hindustanis originate from India (South Asia). Javanese originate from Indonesia (East Asia). Creoles are descendants of West Africans who live in Paramaribo. The Maroons are descendants of West Africans who fled the colonial Dutch forced labour plantations in Suriname and established independent communities in the interior rainforests. They have retained a distinctive identity based on their West African origins. There are no secondary schools in their villages, so they attend schools in Paramaribo. Because of the important differences between these two West African descent groups in terms of lifestyle and history, we have separated these groups. Physical activity was based on the frequency of leisure physical exercise per week outside of school. The same trained final year medical student made anthropometric and blood pressure measurements in all schools.

\section{Data analysis}

Age specific mean systolic BP and diastolic BP levels were determined for boys and girls. Multivariate linear regression analysis enabled age, height and BMI adjusted comparisons of systolic BP and diastolic BP levels to be made between different ethnic groups. Multiple linear regression analyses were performed separately for each ethnic group to assess the relationship between BMI and BP adjusted for other factors. All statistical tests were twotailed and $P$-value $<0.05$ was considered statistically significant. All statistical analyses were performed using SPSS for Windows version 14.2 (SPSS Inc. Chicago, USA) and STATA 9.2 (Stata Corp, College Station, Texas). 
Table I: Characteristics of the study population by ethnicity and sex

\begin{tabular}{|c|c|c|c|c|c|c|}
\hline & Hindustani & Creole & Javanese & Maroon & Mixed & $\mathrm{p}$-value \\
\hline Boys & $(n=86)$ & $(n=85)$ & $(n=60)$ & $(n=4 I)$ & $(n=117)$ & \\
\hline Age $(y)$ & $14.7(1.5)$ & I5.I (1.2) & $15.0(1.2)$ & $15.3(1.2)$ & $14.7(\mid .4)$ & 0.01 \\
\hline Heart rate & $83.6(12.5)$ & $79.1 \quad 12.8)$ & $82.3(12.9)$ & $81.0(12.1)$ & $79.1(11.5)$ & 0.06 \\
\hline Height $(\mathrm{cm})$ & $168.8(9.6)$ & $169.4(9.5)$ & $165.7(8.7)$ & $169.8(8.3)$ & $169.7(8.4)$ & 0.06 \\
\hline Weight $(\mathrm{Kg})$ & $58.1(18.0)$ & $60.6(13.0)$ & $56.1(13.6)$ & $56.0(10.1)$ & $60.0(13.1)$ & 0.20 \\
\hline $\mathrm{BMI}\left(\mathrm{Kg} / \mathrm{m}^{2}\right)$ & $20.1(4.9)$ & $21.0(3.7)$ & $20.2(4.0)$ & $19.3(2.8)$ & $20.7(3.8)$ & 0.18 \\
\hline Overweight/obesity, \% & 24.4 & 21.2 & 18.3 & 7.3 & 18.8 & 0.24 \\
\hline Exercise $\geq 5-7$ days/week, $\%$ & 18.6 & 28.2 & 20.0 & 43.9 & 29.1 & 0.03 \\
\hline Girls & $(n=8 I)$ & $(n=84)$ & $(n=68)$ & $(n=50)$ & $(n=183)$ & \\
\hline Age $(y)$ & $\mid 4.5(\mid .5)$ & | $4.7(1.3)$ & $14.4(1.4)$ & $15.0(1.3)$ & $14.8(1.3)$ & 0.11 \\
\hline Heart rate & $87.4(11.5)$ & $86.4(13.2)$ & $87.0(13.1)$ & $84.4(13.6)$ & $82.6(12.0)$ & 0.02 \\
\hline Height $(\mathrm{cm})$ & $160.1(5.7)$ & $164.4(7.0)$ & $157.8(6.1)$ & $160.6(5.0)$ & $161.4(6.3)$ & 0.001 \\
\hline Weight (Kg) & $51.1(12.3)$ & $56.4(11.4)$ & $48.2(8.1)$ & $55.0(10.9)$ & $53.0(10.1)$ & 0.001 \\
\hline $\mathrm{BMI}\left(\mathrm{Kg} / \mathrm{m}^{2}\right)$ & $19.5(4.0)$ & $20.8(3.8)$ & $19.3(3.0)$ & $21.3(4.1)$ & $20.3(3.5)$ & 0.02 \\
\hline Overweight/obesity, \% & 13.6 & 21.4 & 7.4 & 20.0 & 13.7 & 0.12 \\
\hline Exercise $\geq 5-7$ days/week, $\%$ & 7.4 & 6.0 & 4.4 & 4.0 & 8.2 & 0.74 \\
\hline
\end{tabular}

Results are means (SD) and \%; BMI, Body mass index

Mean systolic BP ( $95 \%$ CI) by age and sex

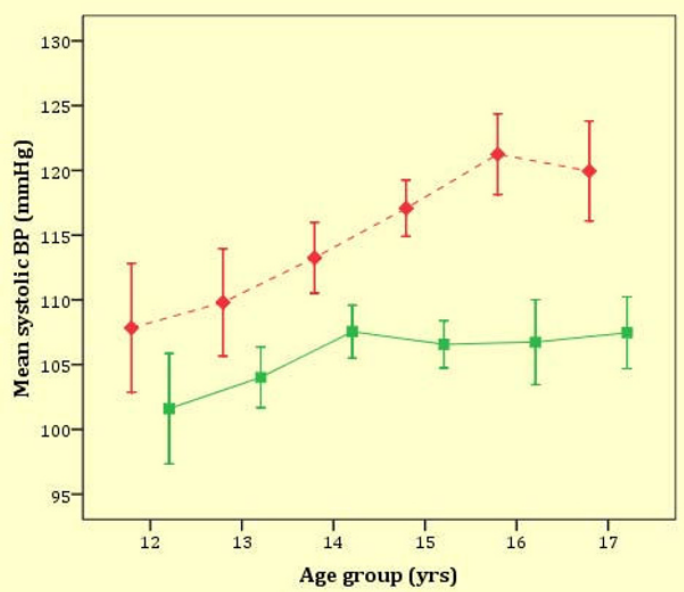

2A
Mean diastolic BP ( $95 \% \mathrm{CI})$ by age and sex

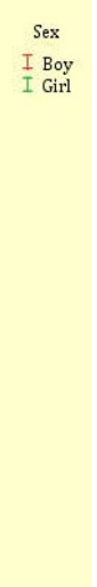

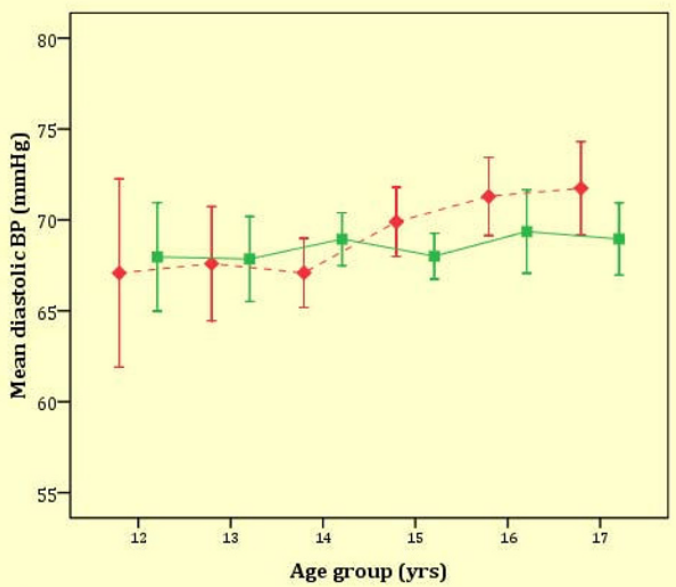

2B

Figure 2

Mean systolic and diastolic BP by age and sex. 


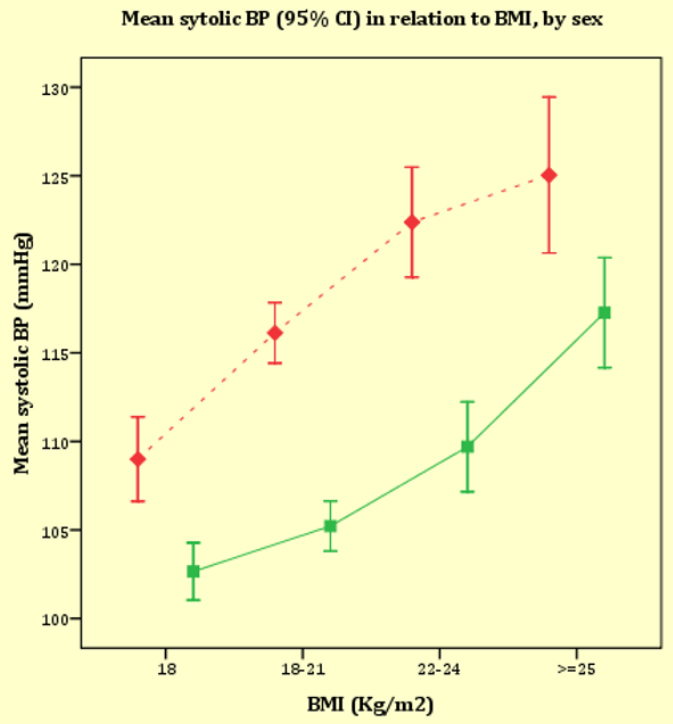

$3 \mathrm{~A}$

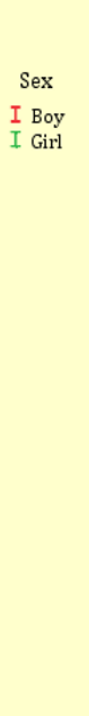

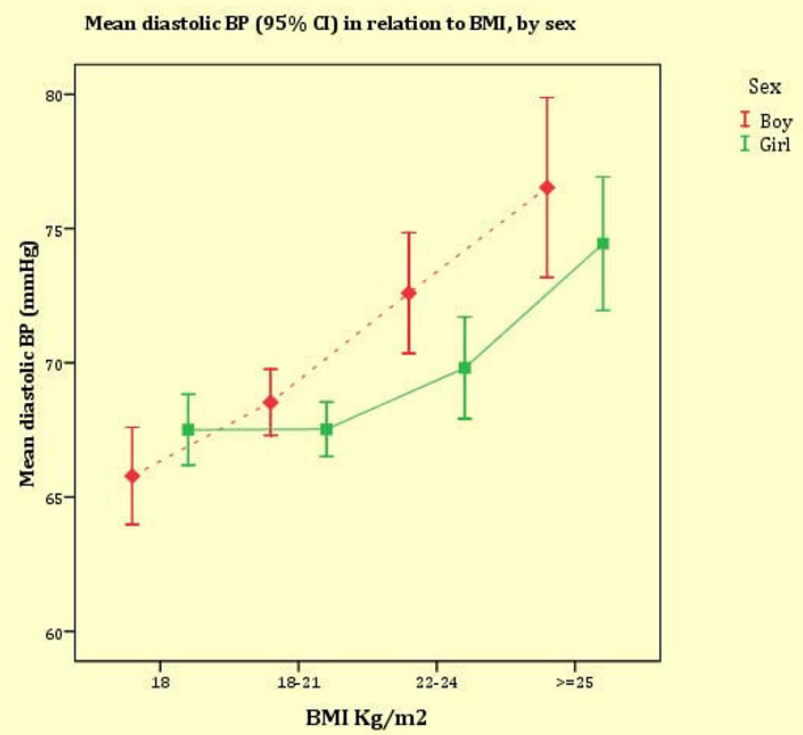

B

Figure 3

Mean systolic and diastolic BP in relation to BMI by sex.

\section{Results}

Table 1 shows the characteristics of the study population by sex and ethnicity. Javanese boys and girls were shorter than all the ethnic groups $(P<0.05)$. Maroon boys had a lower BMI than Creole boys $(P=0.03)$ and Mixed-ethnicity boys $(P=0.05)$. Maroon boys were more likely than other boys to exercise 5-7 days/week. Creole girls were taller than all the ethnic groups $(P<0.001)$. Maroon girls had a higher BMI than Hindustani girls $(P=0.03)$ and Javanese $(P<0.01)$ girls.

\section{Blood pressure levels}

The mean systolic BP and diastolic BP increased with age in both boys and girls (Figure 2a and 2b). The mean systolic BP levels were higher in boys than in girls in all age groups (Figure 2a). The sex differences in diastolic BP were, however, less pronounced (Figure 2b). BMI was associated with systolic BP and diastolic BP in both boys and girls (Figure $3 \mathrm{a}$ and $3 \mathrm{~b}$ ). Table 2 shows the relationships between BMI and systolic BP, and diastolic BP in each ethnic group. BMI was independently associated with systolic BP and diastolic BP in all ethnic groups except for diastolic BP in Maroons.

Figure 4a and 4b show mean systolic BP and diastolic BP by ethnic group and sex. After adjustment for age and height, Maroon boys had a significantly lower mean systolic BP than Creole boys and a lower mean diastolic BP than all the other ethnic groups (Table 3). Further adjust- ment for BMI abolished the significant mean systolic and diastolic BP differences between Maroon boys and other ethnic groups except for the higher mean diastolic BP in Javanese boys $(P=0.04)$. Creole boys had a relatively low age- and height-adjusted mean diastolic BP compared to other boys. After further adjustment for BMI, the differences became more pronounced between Creole and Hindustani boys $(P=0.04)$ and Javanese boys $(P=0.02)$.

Among girls, Javanese had a significantly higher age- and height-adjusted mean diastolic BP than all other ethnic groups except for Hindustani girls. The differences persisted after further adjustment for age, height and BMI ( $P$ $<0.01$ ). Maroon girls had a significantly lower mean diastolic BP than all ethnic groups, except for Creole girls, but only after differences in BMI had been adjusted for. There were no significant differences in mean systolic BP between the ethnic groups.

Maroon boys and Hindustani boys and girls had a relatively low prevalence of high BP compared with other ethnic groups although the differences were not statistically significant (Figure 5a and 5b).

\section{Discussion}

As far as we know, this is the first study on BP patterns amongst adolescents in Suriname, and one of the few studies in adolescents comparing different ethnic groups in a non-industrialised country. Maroon boys had a lower 
Table 2: Multiple regression analysis of factors associated with SBP and DBP for each ethnicity

\begin{tabular}{|c|c|c|c|c|c|c|c|}
\hline & & \multicolumn{2}{|c|}{ Systolic blood pressure } & & \multicolumn{3}{|c|}{ Diastolic blood pressure } \\
\hline & & $\beta$ & $(95 \% \mathrm{Cl})$ & $\mathrm{P}$-value & $\beta$ & $(95 \% \mathrm{Cl})$ & $\mathrm{P}$-value \\
\hline \multicolumn{8}{|c|}{ Hindustani } \\
\hline & $\mathrm{BMI}\left(\mathrm{Kg} / \mathrm{m}^{2}\right)$ & 1.27 & $(0.93,1.60)$ & .000 & 0.79 & $(0.56,1.02)$ & .000 \\
\hline & Girls & -10.76 & $(-13.75,-7.77)$ & .000 & -1.90 & $(-3.99,0.19)$ & .075 \\
\hline & Age & 0.55 & $(-0.46,1.56)$ & .285 & 0.73 & $(0.02,1.43)$ & .043 \\
\hline & Heart rate & 0.27 & $(0.14,0.39)$ & .000 & 0.17 & $(0.08,0.26)$ & .000 \\
\hline & Exercise $\geq 5-7$ days/week & -4.65 & $(-9.02,-0.28)$ & .037 & -2.98 & $(-6.03,0.07)$ & .056 \\
\hline \multicolumn{8}{|l|}{ Creole } \\
\hline & $\mathrm{BMI}\left(\mathrm{Kg} / \mathrm{m}^{2}\right)$ & 1.21 & $(0.75,1.66)$ & .000 & 0.44 & $(0.14,0.73)$ & .004 \\
\hline & Girls & -11.05 & $(-14.61,-7.50)$ & .000 & -2.34 & $(-4.67,-0.01)$ & .049 \\
\hline & Age & 1.84 & $(0.46,3.22)$ & .009 & 0.50 & $(-0.40,1.41)$ & .272 \\
\hline & Heart rate & 0.19 & $(0.06,0.32)$ & .005 & 0.22 & $(0.14,0.31)$ & .000 \\
\hline & Exercise $\geq 5-7$ days/week & -6.06 & $(-10.76,-1.36)$ & .012 & -2.70 & $(-5.78,0.38)$ & .085 \\
\hline \multicolumn{8}{|l|}{ Javanese } \\
\hline & BMI $\left(\mathrm{Kg} / \mathrm{m}^{2}\right)$ & 1.21 & $(0.67,1.75)$ & .000 & 1.14 & $(0.75,1.52)$ & .000 \\
\hline & Girls & -10.65 & $(-14.48,-6.82)$ & .000 & -0.72 & $(-3.43,2.00)$ & .602 \\
\hline & Age & 0.94 & $(-0.43,2.30)$ & .178 & -0.02 & $(-0.99,0.94)$ & .961 \\
\hline & Heart rate & 0.29 & $(0.15,0.43)$ & .000 & 0.23 & $(0.13,0.33)$ & .000 \\
\hline & Exercise $\geq 5-7$ days/week & -6.55 & $(-12.58,-0.51)$ & .034 & -4.28 & $(-8.56,-0.01)$ & .050 \\
\hline \multicolumn{8}{|l|}{ Maroon } \\
\hline & $\mathrm{BMI}\left(\mathrm{Kg} / \mathrm{m}^{2}\right)$ & 0.92 & $(0.09,1.75)$ & .030 & 0.23 & $(-0.32,0.79)$ & .411 \\
\hline & Girls & -8.20 & $(-15.10,-1.29)$ & .021 & -0.71 & $(-5.32,3.90)$ & .760 \\
\hline & Age & 2.10 & $(-0.22,4.43)$ & .075 & 1.75 & $(0.20,3.30)$ & .028 \\
\hline & Heart rate & 0.16 & $(-0.07,0.38)$ & .167 & 0.21 & $(0.06,0.36)$ & .006 \\
\hline & Exercise $\geq 5-7$ days/week & -0.56 & $(-8.42,7.29)$ & .887 & 0.77 & $(-4.48,6.02)$ & .771 \\
\hline \multicolumn{8}{|l|}{ Mixed } \\
\hline & $\mathrm{BMI}\left(\mathrm{Kg} / \mathrm{m}^{2}\right)$ & 1.29 & $(0.94,1.63)$ & .000 & 0.84 & $(0.57,1.12)$ & .000 \\
\hline & Girls & -11.04 & $(-13.66,-8.43)$ & .000 & -2.11 & $(-4.25,0.02)$ & .052 \\
\hline & Age & 1.08 & $(0.13,2.02)$ & .025 & 0.22 & $(-0.55,0.99)$ & .579 \\
\hline & Heart rate & 0.13 & $(0.03,0.23)$ & .013 & 0.17 & $(0.09,0.26)$ & .000 \\
\hline & Exercise $\geq 5-7$ days/week & 0.23 & $(-3.18,3.65)$ & .894 & -2.73 & $(-5.52,0.06)$ & .055 \\
\hline
\end{tabular}

$\mathrm{BMI}$, body mass index, $\mathrm{Cl}$, confidence intervals

BP than all ethnic groups including Creoles with similar West African descent. The lower BP in Maroon boys as compared to other ethnic groups was accounted for by their lower BMI. This might reflect differences in environmental factors such as lifestyle between Maroons and other ethnic groups. Maroon adolescents moved from the Suriname interior to Paramaribo to continue their education. Most Maroon people in Suriname interior still live traditional African lifestyles with female subsistence horticulture and male hunting and fishing. [22] Most Maroon villages are located along the rivers of the interior of Suriname and access is heavily dependent on canoes and other watercraft. [22] This population is therefore isolated and is less exposed to unhealthy urban lifestyles such as excessive consumption of energy-dense foods and frequent use of automobiles $[23,24]$ in urban Paramaribo. It is possible they were still benefiting from their earlier exposure to the traditional lifestyles, which have been suggested to be protective against high BP. [25] Maroon girls, however, had relatively high prevalence of overweight and obesity compared with other ethnic groups. The lower BP in Maroon girls became apparent only after further adjustment for BMI. It is possible that they have adopted different lifestyles such as excessive energy intake and decreasing physical activity once in unban Paramaribo, which may contribute to their rapid increase in BMI and subsequently higher BP. In this study, only $4 \%$ of Maroon girls reported $\geq 5-7$ days/week physical activity outside of school. These findings clearly indicate the need to promote physical activity among this group in Suriname.

Studies in adults have consistently shown higher BP levels in African descent people than in other ethnic groups. $[5,9-11]$ Studies in Suriname and the Netherlands, for example, showed higher BP levels in African-Surinamese than in other ethnic groups. $[8,9]$ In this present study, however, African descent adolescents in Suriname (both Creoles and Maroons) had lower mean diastolic BP levels than other ethnic groups. The lack of higher BP levels in African descent adolescents in Suriname is consistent with the findings in the UK. Studies in the UK show higher BP levels in African descent adults than in other ethnic 


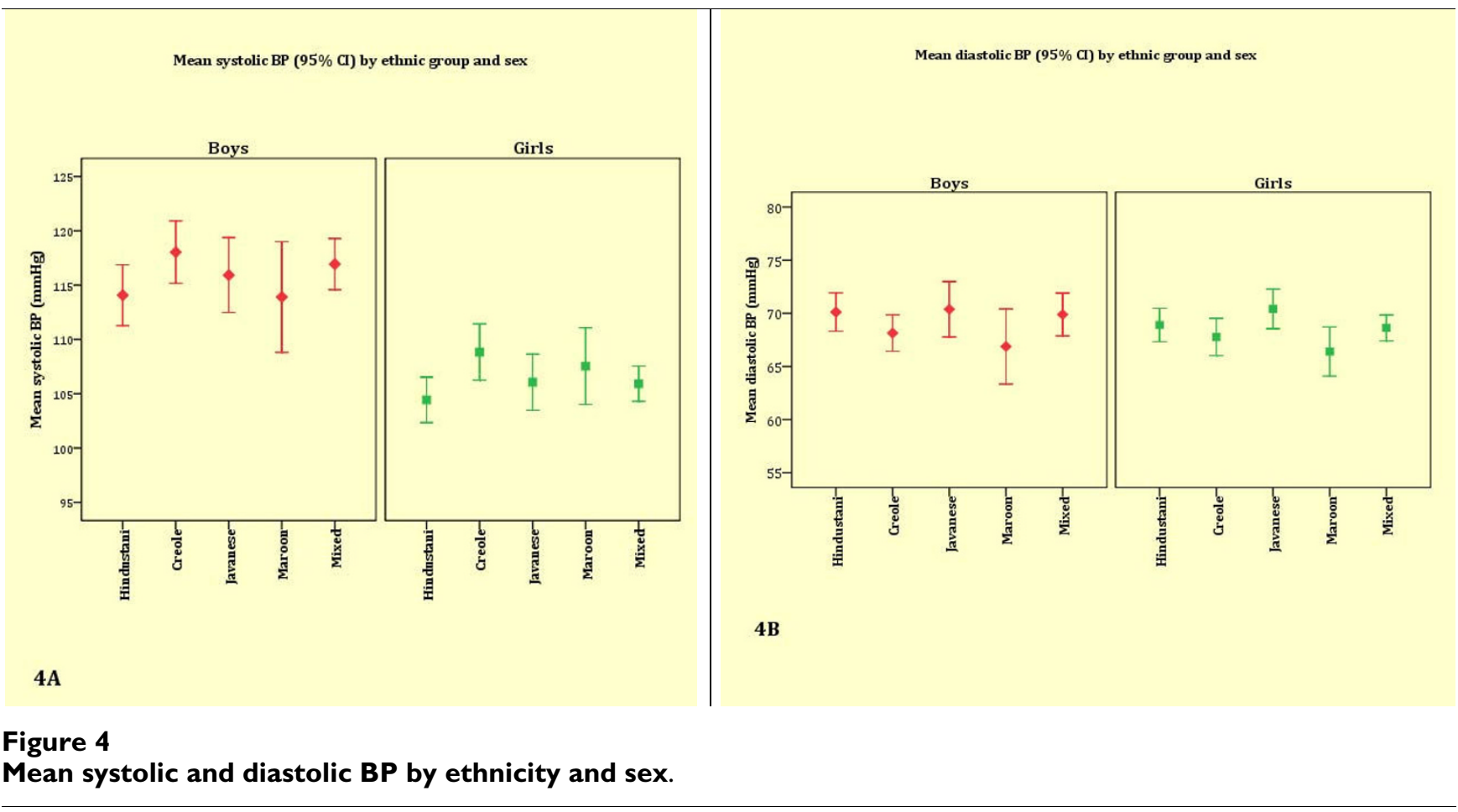

groups. $[10,26]$ By contrast, in adolescents, BP levels were either lower or similar in African descent youth than in other ethnic groups. $[13,14]$ A recent study, for example, found that BP in ethnic minority adolescents was generally lower than in White adolescents except for diastolic $\mathrm{BP}$ among Indian girls in the UK. [13]

The explanations for the different patterns of BP in adolescents and adulthood among African descent populations are unclear and require a cohort study to unravel the pos- sible mechanisms underlying these differences. These observations suggest that environmental factors may be very important. The higher $\mathrm{BP}$ among Javanese adolescents was unexpected given the lower BP reported among the Javanese adult population in Suriname. The reason for the higher mean BP among Javanese adolescents is unclear. One possible explanation may relate to generational differences or changes in lifestyles. This requires further study. Left unchecked, the comparatively high BP among Javanese adolescents may abolish or reverse the

Table 3: Adjusted mean systolic and diastolic blood pressure levels by ethnicity and sex

\begin{tabular}{|c|c|c|c|c|}
\hline & \multicolumn{2}{|c|}{ Systolic blood pressure $[95 \% \mathrm{CI}]$} & \multicolumn{2}{|c|}{ Diastolic blood pressure $[95 \% \mathrm{Cl}]$} \\
\hline & Model I & Model II & Model I & Model II \\
\hline \multicolumn{5}{|l|}{ Boys } \\
\hline Hindustani & $114.2(111.6-116.8)$ & $114.4(112.0-116.9)$ & $70.0(68.1-72.0)$ & $70.2(68.3-72.1)$ \\
\hline Creole & $117.2(114.5-119.8)$ & $116.7(114.2-119.1)$ & $67.6(65.4-69.9)$ & $67.3(65.4-69.2)$ \\
\hline Javanese & $117.3(1 \mid 4.1-120.4)$ & $117.3(114.3-120.2)$ & $70.9(68.5-73.3)$ & $70.9(68.6-73.2)$ \\
\hline Maroon & $112.5(108.8-116.3)$ & $114.0(110.5-117.6)$ & $66.1(63.2-69.0)$ & $67.1(64.3-69.9)$ \\
\hline Mixed-ethnicity & $116.5(114.3-118.8)$ & $116.2(1|4.1-1| 18.3)$ & $69.6(67.9-71.4)$ & $69.4(67.8-71.0)$ \\
\hline \multicolumn{5}{|l|}{ Girls } \\
\hline Hindustani & $104.5(102.1-106.9)$ & $105.0(102.8-107.2)$ & $68.8(67.1-70.6)$ & $69.1(67.4-70.7)$ \\
\hline Creole & $107.9(105.4-110.3)$ & $107.2(105.0-109.4)$ & $67.2(65.4-68.9)$ & $66.8(65.1-68.5)$ \\
\hline Javanese & $106.7(104.1-109.4)$ & $107.7(105.0-110.2)$ & $70.6(68.7-72.6)$ & $71.2(69.3-73.0)$ \\
\hline Maroon & $107.3(104.2-110.4)$ & $106.2(103.4-109.0)$ & $66.1(64.0-68.4)$ & $65.6(63.4-67.9)$ \\
\hline Mixed-ethnicity & $105.6(103.9-107.1)$ & $105.6(104.1-107.1)$ & $68.3(67.2-69.5)$ & $68.3(67.2-69.4)$ \\
\hline
\end{tabular}

Model I (adjusted for age and height) model II (model I plus BMI); Cl, confidence intervals 

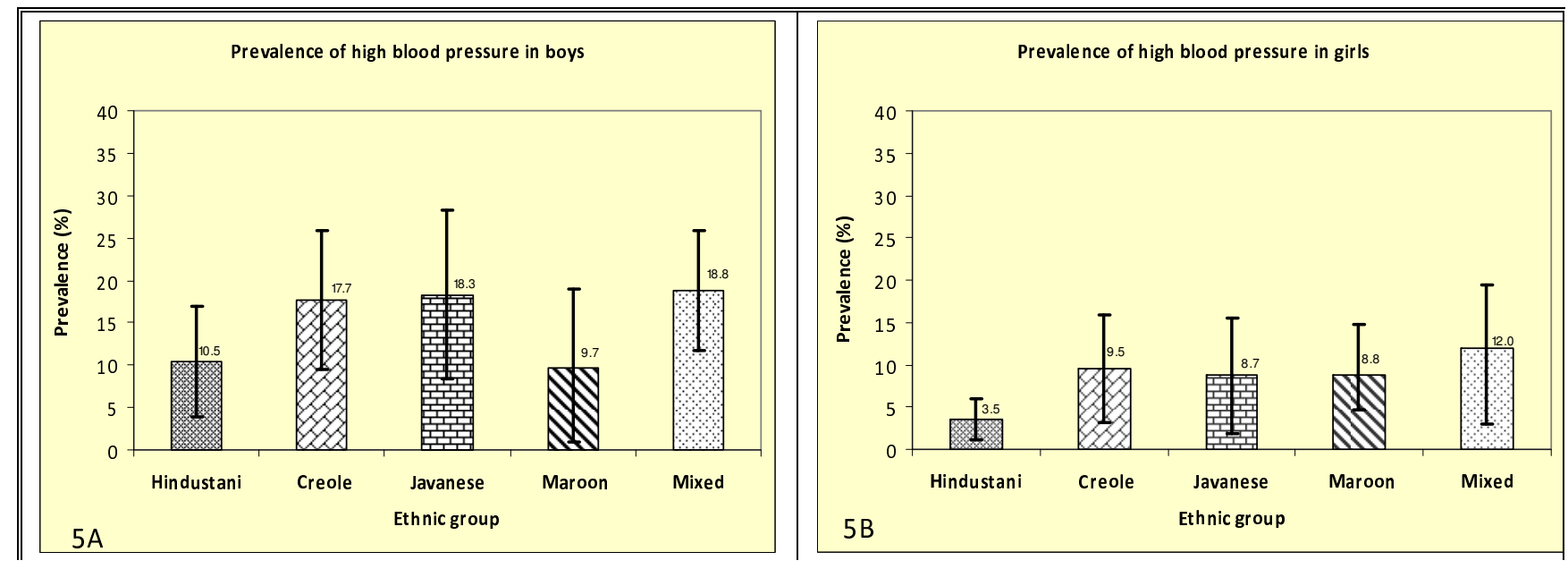

Figure 5

Prevalence of high BP in boys and girls.

current lower BP advantage enjoyed by the Javanese adult population in Suriname. These observations clearly indicate the need for early intervention in adolescents for preventing high $\mathrm{BP}$ in later life. [13]

The relationship between BMI and BP is well established in children and adolescents. [15-17] The strong and independent relationship between BMI and BP in our present study is consistent with previous findings. Although the mechanisms by which BMI may lead to high BP are not well understood, it is now generally recognised that high BMI significantly increases the risk of high BP. [27] Sinaiko and colleagues' prospective study showed that increases in BMI in early life were significantly related to an increased risk of high BP and other CVD in adulthood. [27] Our findings clearly indicate the need to prevent the increasing prevalence of overweight and obesity especially in Maroon girls early in life to prevent future sequelae of overweight/obesity related diseases.

Our study has limitations. As in many epidemiological studies, our BP level was based on an average of two measurements at a single visit. A more precise estimate of $\mathrm{BP}$ level would be obtained by multiple measurements obtained during several visits. Also, evidence suggests that during puberty BP increases more rapidly, with a significant gender difference in the age of onset. [28] In the present study, pubertal status was not assessed and this may affect the study conclusions. Nevertheless, in the recent UK study, late puberty was not associated with high BP in ethnic minority groups. [13] Another possible limitation is the combined mixed-ethnicities due to the small study samples. It is possible that BP patterns differ among these different ethnic groups. [29] Future studies should assess this possibility. In addition, social circumstances between the groups were not assessed, which might also affect our study conclusions. Despite these limitations, our present findings provide very important insights into ethnic differences in BP in adolescents in non-industrialised setting.

\section{Conclusion}

The study findings indicate a higher mean BP among Hindustani boys and Javanese boys and girls whereas in the adult population these groups have lower mean BP levels in Suriname. BMI was positively related to BP in all the ethnic groups. These observations underscore the urgent need for public health measures early in life to prevent high BP and its sequelae in later life. BP reductions in adolescents can be achieved by weight loss through reducing excessive energy intake [30] and increasing physical activity strategies. [31] These cost-effective measures may lead to an important reduction in BP in adolescents thereby sparing the next generation from hypertension related complications [32].

\section{Competing interests}

The authors declare that they have no competing interests.

\section{Authors' contributions}

All were responsible for study concept and design. EO and WJ were responsible for data collection. CA, JFW, EO and KS were responsible for analysis and interpretation of data. CA drafted the manuscript and all were involved in critical revision of the manuscript. All authors read and approved the final manuscript. 


\section{Acknowledgements}

We thank all the school children and the teachers who made this study possible. We thank Dr A. de Jonge (TNO Quality of life) for proving useful comments on an earlier draft.

\section{References}

I. Gaziano TA: Reducing the growing burden of cardiovascular disease in the developing world. Health Aff 2007, 26: I 3-24.

2. Murray C], Lopez AD: Mortality by cause for eight regions of the world: Global Burden of Disease Study. Lancet 1997, 349: |436- |442.

3. Bao W, Threefoot SA, Srinivasan SR, Berenson GS: Essential hypertension predicted by tracking of elevated blood pressure from childhood to adulthood: the Bogalusa Heart Study. Am J Hypertens 1995, 8:657-65.

4. Lauer RM, Clarke WR: Childhood risk factors for high adult blood pressure: the Muscatine Study. Pediatrics 1989 , 84:633-4I.

5. Lane DA, Gill P: Ethnicity and tracking blood pressure in children. I Hum Hypertens 2004, I 8:223-8.

6. Daniels SR, Loggie JM, Khoury P, Kimball TR: Left ventricular geometry and severe left ventricular hypertrophy in children and adolescents with essential hypertension. Circulation 1998 , 97:|907-II.

7. National High Blood Pressure Education Program Working Group on High Blood Pressure in Children and Adolescents: The fourth report on the diagnosis, evaluation, and treatment of high blood pressure in children and adolescents. Pediatrics 2004, I | 4(2 Suppl 4th Report):555-76.

8. Asin-Oostburg V: Diabetes in Suriname (II PAHO- DOTA Workshop on Quality of Diabetes Care). Diabetes Research Institute, University of Miami, USA; 2003.

9. Agyemang C, Bindraban N, Mairuhu G, Montfrans G, Koopmans R Stronks R: Prevalence, Awareness, Treatment and Control of Hypertension among ethnic minority groups in Amsterdam, the Netherlands - The SUNSET study. J Hypertens 2005 , 23:1971-1977.

10. Agyemang C, Bhopal R: Is the blood pressure of people from African origin adults in the UK higher or lower than that in European origin white people? A review of cross sectional data. J Hum Hypertens 2003, I 7:523-534.

II. Hajjar I, Kotchen TA: Trends in prevalence, awareness, treatment and control of hypertension in the United States, 1998-2000. JAMA 2003, 290:199-206.

12. Agyemang C, Bhopal RS: Is the blood pressure of South Asian adults in the UK higher or lower than that in European white adults? A review of cross-sectional data. J Hum Hypertens 2002. | 6:739-75 |

13. Harding S, Maynard M, Cruickshank JK, Gray L: Anthropometry and blood pressure differences in black Caribbean, African, South Asian and white adolescents: the MRC DASH study. J Hypertens 2006, 24:|507-|4.

14. Agyemang $C$, Bhopal $R$, Bruijnzeels $M$ : Do variations in blood pressures of South Asian, African and Chinese descent children reflect those of the adult populations in the UK? A review of cross-sectional data. I Hum Hypertens 2004, I 8:229-37.

15. Freedman DS, Dietz WH, Srinivasan SR, Berenson GS: The relation of overweight to cardiovascular risk factors among children and adolescents: the Bogalusa Heart Study. Pediatrics 1999 I03(6 Part I): I |75-I I82.

16. Rosner B, Prineas R, Daniels SR, Loggie J: Blood pressure differ ences between blacks and whites in relation to body size among US children and adolescents. Am J Epidemiol 2000 |5 |:1007-1019.

17. Sorof JM, Lai D, Turner J, Poffenbarger T, Portman RJ: Overweight, ethnicity, and the prevalence of hypertension in school-aged children. Pediatrics 2004, I I3(3 Part I):475-482.

18. Agyemang C, Redekop WK, Owusu-Dabo E, Bruijnzeels MA: Blood pressure patterns in rural, semi-urban and urban children in the Ashanti region of Ghana, West Africa. BMC Public Health 2005, 5:114

19. Chiolero A, Madeleine G, Gabriel A, Burnier M, Paccaud F Bovet P. Prevalence of elevated blood pressure and association with overweight in children of a rapidly developing country. J Hum Hypertens 2007, 2 I : | 20- I 27
20. Cole T], Bellizzi MC, Flegal KM, Dietz WH: Establishing a standard definition for child overweight and obesity worldwide: international survey. BMJ 2000, 320(7244): I 240-3

21. National High Blood Pressure Education Program Working Group on High Blood Pressure in Children and Adolescents: The fourth report on the diagnosis, evaluation, and treatment of high blood pressure in children and adolescents. Pediatrics 2004 , I | 4:555-576.

22. St-Hilaire A: Global incorporation and cultural survival: The Surinamese Maroon at the margins of the world-system. World-system Research 2000, 6:101-131.

23. Popkin BM: Global nutrition dynamics: the world is shifting rapidly toward a diet linked with noncommunicable diseases. Am J Clin Nutr 2006, 84:289-298.

24. Agyemang C, Owusu-Dabo E, de Jonge A, Martins D, Ogedegbe G Stronks K: Overweight and obesity among $\mathrm{Ghanaian}$ residents in The Netherlands: how do they weigh against their urban and rural counterparts in Ghana? Public Health Nutr 2008:1-8. Published Online First, doi: I0. I0 I 7/S I 368980008003510

25. Shaper AG, Wright DH, Kyobe J: Blood pressure and body build in three nomadic tribes of northern Kenya. East Afr Med J 1969, 46:273-8I.

26. Lane DA, Lip GY: Ethnic differences in hypertension and blood pressure control in the UK. QJM 200I, 94:39I-6.

27. Sinaiko AR, Donahue RP, Jacobs DR Jr, Prineas RJ: Relation of weight and rate of increase in weight during childhood and adolescence to body size, blood pressure, fasting insulin, and lipids in young adults. The Minneapolis Children's Blood Pressure Study. Circulation 1999, 99:|47|-6.

28. Voors AW, Foster TA, Frerichs RR, Webber LS, Berenson GS: Studies of blood pressures in children, ages 5-14 years, in a total biracial community: the Bogalusa heart study. Circulation 1976, 54:319-327.

29. Agyemang C, Bhopal R, Bruijnzeels M: Negro, Black, Black African, African Caribbean, African American or what? Labelling African origin populations in the health arena in the 2 Ist century. I Epidemiol Community Health 2005, 59:1014-8.

30. Gallist S, Sudi KM, Aigner R, Borkenstein $M$ : Changes in serum interleukin- 6 concentrations in obese children and adolescents during a weight reduction program. Int J Obes Relat Metab Disord 2001, 25:1640-1643.

31. Rocchini A, Katch V, Anderson J, Hinderliter J, Becque D, Martin M: Blood pressure in obese adolescents: effect of weight loss. Pediatrics 1988, 82:16-23.

32. Agyemang C, Vaarties I, Bots ML, van Valkengoed IG, de Munter JS, de Bruin A, Berger-van Sijl M, Reitsma JB, Stronks K: Risk of death after first admission for cardiovascular diseases by country of birth in The Netherlands: a nationwide record-linked retrospective cohort study. Heart 2009, 95:747-53.

\section{Pre-publication history}

The pre-publication history for this paper can be accessed here

\section{http://www.biomedcentral.com/1471-2261/9/19/prepub}

Publish with Biomed Central and every scientist can read your work free of charge

"BioMed Central will be the most significant development for disseminating the results of biomedical research in our lifetime. "

Sir Paul Nurse, Cancer Research UK

Your research papers will be:

- available free of charge to the entire biomedical community

- peer reviewed and published immediately upon acceptance

- cited in PubMed and archived on PubMed Central

- yours - you keep the copyright
BioMedcentral 